\title{
PESQUISAS DE FORMAÇÃO CONTINUADA DE PROFESSORES COM INTERFACES NA SEXUALIDADE E NO CINEMA
}

\author{
H.S.G. RAMOS, A. RODRIGUES \\ Universidade Federal do Espírito Santo \\ hugo-sgramos@hotmail.com
}

Artigo submetido em 07/03/2017 e aceito em 14/08/2019

DOI: $10.15628 /$ holos.2019.5722

\section{RESUMO}

Considerando a formação continuada de professores sobre a temática de sexualidade, tendo o cinema como um dispositivo, neste texto é apresentado um estudo bibliográfico que analisou produções acadêmicas sobre essas temáticas. Busca-se compreender como se configuram as pesquisas que associam a tríade referente à formação continuada, ao cinema e à sexualidade, selecionando trabalhos no Banco de Teses e Dissertações da CAPES e nos grupos de trabalho 16 e 23 da ANPEd. As análises do corpus de dados acenam para a necessidade de investimentos em mais ações de formação continuada a partir do cinema que tematizam à sexualidade. Além disso, acredita-se ser necessário experimentar formações sem querer capacitar, sem verdades universais, transmissão, conscientização, autoridade e com dicotomias entre teoria e prática.

PALAVRAS-CHAVE: Formação Continuada de Professores, Sexualidade, Cinema.

\section{CONTINUED FORMATION OF TEACHERS RESEARCHES WITH INTERFACES ON SEXUALITY AND THE CINEMA}

\begin{abstract}
Taking into account the continued formation of teachers on a theme of sexuality, having the cinema as a device, in this text is a bibliographic study that analyzed academic productions on thematic. We search how they are configured as research that associates the triad with regard to continuing formation, cinema and sexuality, selecting works in the Bank of Thesis and Dissertations of CAPES and in working groups 16 and 23 of ANPEd. As
\end{abstract}

analyzes of the data corpus call for a need for investments in continuing formation actions that focus on sexuality by cinema. In addition, it is believed that it is necessary to try out formations without wanting to train, without universal truths, transmission, awareness, authority and with dichotomies between theory and practice.

KEYWORDS: Continued Formation, Sexuality, Cinema. 


\section{INTRODUÇÃO}

Para um maior aprofundamento das produções acadêmicas produzidos sobre formação continuada de professores em interface com a sexualidade e o cinema, neste artigo apresentamos um estudo bibliográfico. Nessa proposição, promovemos uma busca nos trabalhos apresentados na Associação Nacional de Pesquisa em Educação (ANPED), precisamente no Grupo de Trabalho (GT) de Gênero, Sexualidade e Educação e no GT Educação e Comunicação, bem como na página da Coordenação de Aperfeiçoamento de Pessoal em nível Superior (CAPES). Essa última instância traz as dissertações de Mestrado e as teses de Doutorado defendidas nos Programas de Pós-Graduação em Educação de agências de formação brasileiras, sejam públicas ou privadas. Destacamos a relevância da ANPED e CAPES quanto ao fomento à produção acadêmica.

Dessa forma, elencamos algumas noções norteadoras: como se configura a articulação entre as temáticas de formação continuada de professores com a sexualidade e o cinema? Quais concepções de formação, sexualidade e cinema orientam essas pesquisas? Quais aspectos ganham destaque nos estudos, no que se refere à formação continuada, sexualidade e cinema? Com essas indagações buscamos identificar contribuições para o campo da formação continuada de professores direcionadas à sexualidade e o cinema.

Compreendendo, de acordo com Sennet (apud DIAS, 2011) que vivemos em uma sociedade da capacitação em que os trabalhadores estão em permanente estado de capacitação, e quando adquirem as aptidões necessárias se tornam obsoletos rapidamente. Assim, logo entram no ciclo novamente, em que precisam de mais capacitação para se adaptar às constantes modificações do capitalismo. Esse é um modelo que se faz pelo regime de inacabamento constante e provisório, o que inclui as formações continuadas de professores. Por outro lado, é possível pensar uma formação, mas que busque permanentemente a invenção de problemas, onde o si se constitui e o mundo coemerge. Trata-se de uma política cognitiva entendendo a cognição como invenção de si e do mundo (KASTRUP, 2005).

Acredita-se que o cinema pode ativar a invenção de problemas, a experiência de problematização numa formação. Para tanto, as imagens não devem ser compreendidas apenas como representações, estando no plano das formas. As imagens emitem signos - que "segundo Deleuze é aquilo que exerce sobre a subjetividade uma ação direta, sem a mediação da representação" (KASTRUP, 2001:20) - que afetam o sujeito. Ou seja, força o movimento da subjetividade.

Com esses pressupostos, organizamos este estudo delimitando o período de 2010-2015, em que quatro trabalhos foram apresentados na ANPED e quatro dissertações e teses sinalizavam discussões sobre formação continuada de professores em interface com sexualidade ou cinema. Para a seleção das quatro dissertações e teses, selecionou, primeiramente, três-conceitos chaves: Formação Continuada de Professores, Sexualidade e Cinema. Nenhum trabalho que envolvesse as três temáticas foi encontrado. Para uma maior apuração dessa produção, buscamos então o conceito "formação continuada de professores", que trouxe todos os trabalhos produzidos, um total de 661, demandando que recorresse, inicialmente, à leitura dos títulos, dos resumos e de alguns trabalhos completos. Diante de descobrir que nenhum trabalho reunia as três temáticas, decidimos 
dividir os estudos em dois eixos, a saber, o primeiro com pesquisas que abordam a formação continuada de professores e a sexualidade, já o segundo que perspectivam a formação continuada com a temática do cinema.

\section{A FORMAÇÃO CONTINUADA DE PROFESSORES COM A TEMÁTICA DA SEXUALIDADE}

O primeiro eixo, destacamos a Tese de Doutorado de Santos (2011). A autora investigou qual a origem e significado dos saberes docentes acerca da sexualidade e buscou compreender como têm sido as práticas pedagógicas diante de manifestações da sexualidade de crianças e adolescentes. Tendo como sujeitos de sua pesquisa um grupo heterogêneo, professoras que participaram de um curso de pós-graduação Lato Sensu que fizeram uma disciplina intitulada Orientação Sexual na Educação; profissionais da educação que participaram de um curso de Pós Graduação da Universidade de Lisboa; e professoras que atuam na formação inicial e/ou continuada.

Santos (2011) observou que a sensibilidade e a intuição foram marcas centrais nos discursos dos professores e que são principalmente esses saberes que têm guiado suas práticas pedagógicas, considerando que alegaram que os conteúdos e discussões realizados nos espaços de formações não foram suficientes frente a algumas situações do cotidiano que envolviam a sexualidade. Nesse contexto, pode-se perceber que nenhum curso de formação, seja inicial ou continuada, conseguirá dar conta da efemeridade, imprevisibilidade, dinamicidade, incerteza, complexidade, enfim, do intempestivo que é o vivido no cotidiano das escolas. Em vez de procurar fórmulas para solução de problemas deve-se investir em formações pautadas na problematização e invenção de problemas, no compartilhamento das experiências.

Por último, a autora destaca algumas possíveis causas do não envolvimento e posicionamento nas práticas pedagógicas de professores brasileiros com a temática:

A falta de espaço na formação continuada, de forma sistematizada sobre a temática;
observam que os poucos momentos de formação organizados pelas unidades educativas
e/ou Secretarias de Educação não proporcionam a participação de todos os professores; A
falta de assessoramento às suas práticas pedagógicas voltadas às questões da sexualidade;
Uma preocupação excessiva com a reação de pais e mães no que tange às manifestações
da sexualidade por parte dos alunos e/ou às suas intervenções pedagógicas diante de tais
manifestações; A ausência atuante da equipe pedagógica nas unidades educativas com
relação à temática (SANTOS, 2011:177).

Já o estudo de Santos (2012) objetiva compreender o desenvolvimento do curso de formação continuada "Gênero, sexualidade e diversidade sexual" ofertado para Rede Municipal de Educação do município de Juiz de Fora. Para isso, a pesquisadora cursou a formação e realizou entrevistas com os organizadores e formadores, além dos professores participantes.

A pesquisadora constatou que no início do curso houve um grande número de participantes, mas posteriormente ocorreu uma evasão. Quando indagou este fato nas entrevistas realizadas com os organizadores e professores, percebeu que os participantes ainda procuram o curso almejando "receitas de bolo", ou seja, soluções "fáceis" para seus problemas e dificuldades, indo de encontro ao objetivo do curso, que era a reflexão da própria prática pedagógica, de tomar o cotidiano como 
objeto de pesquisa. Outro objetivo do curso também foi trabalhar conceitos de gênero, sexualidade, diversidade e identidade numa perspectiva pós-estruturalista e dos estudos culturais.

Os resultados da pesquisa possibilitaram perceber que o curso despertou a capacidade de observação da temática tanto no contexto escolar como em outros contextos, extrapolando o campo profissional. Além disso, o curso foi avaliado como positivo, pois "contribuiu para subsidiar o trabalho de professores e professoras no enfrentamento de preconceitos e de intolerância que se passam nas escolas" (SANTOS, 2012:115). A autora salienta que uma questão destacada pelos próprios professores foi o compartilhamento de experiências de diferentes realidades escolares, ao longo do curso, que permitiu, dessa forma, ocorrer uma aproximação também da prática, e não ficar somente na teoria.

Trazendo a homossexualidade para o debate, a pesquisa de Doutorado de Granúzzio (2012) analisa em um programa de formação continuada, denominado de horário de trabalho pedagógico coletivo, as significações de professores sobre homossexualidade. Esta formação era uma proposta organizada por uma Organização Não-Governamental (ONG) que desenvolvia ações sócioeducativas com enfoque em direitos humanos e sexualidade. Na escola pesquisada foi produzido o projeto "Diversidade", que consistia, em meio à formação continuada de professores, discutir o tema da sexualidade/homossexualidade. Com relação à abordagem metodológica, Granúzzio (2012) utiliza diferentes instrumentos: questionários, entrevistas coletivas e individuais com a direção escolar, coordenação, professores, acompanhamento das ações formativas, sessões de estudos, além do diário de campo.

A pesquisa afirma que os professores relataram casos de silenciamento e omissão diante de discriminações e preconceitos sofridos por adolescentes (alunos) homossexuais. Além disso, de acordo com a autora, os dados revelaram que os sentidos atribuídos por professores sobre a questão da sexualidade e homossexualidade dos alunos se dão:

uns, preocupados, devido a questões religiosas e familiares; alguns, inseguros e ainda
despreparados para uma prática docente que respeite a diversidade sexual; e outros mais
se perguntando se é papel da escola trabalhar questões que julgam ser de âmbito pessoal
e não público, mesmo reconhecendo que consequências do silenciamento são de impacto
coletivo e público. (GRANÚZZIO, 2012:142)

Com este estudo foi evidenciado um modelo de formação continuada que não conseguiu superar o modelo clássico, sem promover condições para mudanças emancipatórias. Ademais, a reflexão que houve para a pesquisadora deveria ser pautada nas atividades práticas dos docentes e com a elaboração e execução de atividades junto aos alunos.

Outro trabalho é o efetuado por Rizzato (2012), que realizou um recorte do mestrado que teve como objetivo compreender as percepções de professores sobre as questões de gênero, sexualidade e homofobia e o modo como lidam com essas temáticas em sua prática como educadores/as. No trabalho apresentado na ANPED, buscou reconhecer o processo de construção da experiência social em diversidade sexual e as interlocuções estabelecidas pelos/as professores/as com diferentes vivências pessoais e profissionais, esferas sociais e padrões de comportamentos sexuais postos socialmente. 
O foco dos sujeitos dessa pesquisa foi os professores da rede estadual de ensino de São Paulo, participantes do curso intitulado Convivendo com a Diversidade Sexual na escola de uma política de formação continuada em gênero e sexualidade do MEC. Com relação à abordagem metodológica, a autora, conforme disse, "coletou dados" por meio de um questionário aplicado aos 21 professores/as participantes do curso que aceitaram fazer parte da pesquisa.

Rizzato (2012) aponta que por meio da análise dos questionários, foi possível perceber que a abordagem de gênero e sexualidade na escola nem sempre implica trabalhar com a diversidade sexual e construir uma experiência social que identifique e enfrente a homofobia. Além disso, ela percebeu diferentes percepções sobre a homofobia na escola, assim como níveis distintos de envolvimento com a temática apresentando muitas contradições e estereótipos.

Segundo a autora, o resultado da sua pesquisa mostra uma forte presença de ideias do senso comum nos relatos, "[...] o discurso da maioria dos/as professores/as reflete um saber sobre a sexualidade em que qualquer expressão que fuja aos padrões heterossexuais e naturais é considerada anormal". Ressalta, ainda, a força do discurso político e religioso nas falas dos professores e em suas percepções sobre a homofobia, assim como a marca religiosa nas observações distintas que tecem à respeito da diversidade sexual.

O estudo de Ribeiro (2012), por sua vez, problematiza as falas de educadoras que atuam na Educação Infantil concebendo-as como enunciados. O conceito de enunciado é fundamental nessa pesquisa, e a autora o trabalha a partir de Foucault.

Os enunciados são de educadoras que participaram de um curso de formação continuada na temática de gênero e sexualidade na infância. Para a referida pesquisa, foi utilizado como instrumento metodológico o registro de depoimentos individuais das educadoras que apresentavam cenas do cotidiano da Educação Infantil na temática de gênero e sexualidade. A autora buscou analisar o material da pesquisa numa tentativa de transversalidade das falas das educadoras com as potencialidades do conceito de enunciado de Foucault.

O estudo, como a própria autora diz, "termina com o que não tem fim", pois ainda há muitas problematizações a serem feitas referentes à pesquisa com as educadoras que atuam na Educação Infantil (EI). E pondera que houve uma conquista de uma legislação para a El, mas que ainda há muito para conquistar em relação à temática de gênero e sexualidade.

Partindo de outro universo, o estudo de Castro (2012), que, por meio de um curso de extensão realizado pela Universidade Federal do Rio de Janeiro chamado Diversidade Sexual $e$ Identidades de Gênero na Escola, analisou os registros dos profissionais da educação deste curso quando realizaram atividades didáticas - com foco na discussão de questões ligadas a gênero e diversidade sexual. Tendo em vista que essas intervenções pedagógicas eram parte da metodologia de tal curso de extensão.

De acordo com o autor, como o intuito não era produzir uma análise profunda de uma única experiência e sim produzir uma leitura ampla das intervenções pedagógicas, optaram como metodologia a análise de conteúdo. Foram analisados na referida pesquisa 37 cadernos/diários de diversos profissionais da educação e de diferentes níveis de ensino. 
O resultado da pesquisa, segundo Castro (2012), sinalizou que a questão da homossexualidade e não exatamente da diversidade sexual continua aparecendo desarticulado de outros conteúdos escolares. Além disso, o autor coloca que não há caminho certo, e o que se tem é um longo caminho a ser percorrido

não apenas na desconstrução das violências e desigualdades de gênero e sexualidade na escola, mas na construção de uma pedagogia que tenha o reconhecimento da diferença, a promoção da reflexão crítica e a superação das desigualdades como meio e objetivo. (CASTRO, 2012, p.17)

E conclui o estudo, afirmando que houve muitas aprendizagens sobre o que "não devemos fazer", mas que há ainda muito que descobrir sobre o que "deve ser feito e como fazê-lo".

\section{FORMAÇÃO CONTINUADA DE PROFESSORES EM DIÁLOGO COM O CINEMA}

A pesquisa de Bassalo (2011) foi a única que trouxe uma articulação da discussão da (homo)sexualidade a partir do cinema, embora não seja um curso de formação continuada de professores em sexualidade (exclusivamente) a partir do cinema. A pesquisa procurou compreender os significados e sentidos sobre homossexualidade a partir do filme Milk: a voz da igualdade, uma dentre as várias atividades do curso. Teve como objeto de análise os professores da Educação básica da Secretaria de Educação do Distrito Federal que participaram do curso Gênero e Diversidade da Escola, que integra a Rede de Educação para a Diversidade do Ministério da Educação.

É um curso ofertado na modalidade à distância-ambiente virtual via plataforma moodle-por distintas universidades do país através dos pólos da Universidade Aberta do Brasil. A autora destaca que para realizar a análise dos dados foi utilizado o Método Documentário o que possibilitou conceber o fórum de debate online como espaço de experiência, além de tornar os discursos dos cursistas como documentos textuais.

Os resultados das análises permitiram constatar três grupos distintos de professores:

Um grupo com posturas completamente homofóbicas, que negam a diversidade sexual, outro que demonstra uma crescente aceitação da diversidade sexual embora evidencie estranheza, e aquelas que já têm consolidado uma interpretação baseada no reconhecimento da diferença e na igualdade e assumem uma postura de defesa dos direitos dos homossexuais. Neste último grupo se inserem aqueles que compreendem a escola como instituição que não pode silenciar nem ser omissa. (BASSOLA, 2011:12)

A pesquisadora concluiu que ainda é necessário que os professores assumam o compromisso ético de demonstrarem que as formas de orientação sexual não podem ser hierarquizadas e que a heteronormatividade conduz à homofobia. Além disso, destacou a importância de se localizar histórica e socialmente as formas de discriminação e exclusão, pois, assim, pode-se desconstruí-las e superá-las.

Encerra-se esse percurso de análise com a pesquisa de Doutorado de Kerr Junior (2012), que na companhia de autores da filosofia da diferença, da arte, do cinema e da formação docente investiga sobre (trans)formação docente, experiência estética e cinema-tempo. O autor coloca algumas perguntas que movimentam o trabalho da tese: "Como trabalhar a (trans)formação docente buscando encontrar o que não se sabe? Como permitir um encontro quando se quer 
apostar no esquecimento? Como a imagem do cinema pode potencializar o conceito de arte como memória curta e imagem-cristal? Como a educação de professores pode ser afetada pela concepção de arte como sensação, educação como esquecimento e cinema como imagem ótica e sonora pura? (KERR JUNIOR, 2012: 12)".

Para desenvolver a pesquisa houve a realização de oficinas com as professoras de arte da rede municipal de Pelotas e com professoras da rede municipal de Canoas/RS que faziam parte de uma formação continuada. Juntamente com experiências com alunas do estágio supervisionado de Artes Visuais e com alunas da disciplina de "Experiência Estética" do Instituto Federal de Educação e Tecnologia Sul-Rio-Grandense (IFSUL). Como metodologia foi realizada o uso da cartografia.

Nos resultados do estudo, o autor coloca a necessidade de compor uma nova forma de ensinar e aprender que passe pelas imagens, afecções e que dialogue formação e subjetividade. Ademais, sinaliza uma aposta em uma (trans)formação inventiva em que "formadores e formados apostem em inventar seu próprio processo com ética-estética-política, expandindo a possibilidade de deformação e (trans)formação [...] (KERR JUNIOR, 2012: 162)". Essa tese se mostra diferente de formações que possuem como modelo a norma hegemônica, é o estudo que mais se aproxima à perspectiva de formação docente deste filmepesquisa.

\section{CONSIDERAÇÕES FINAIS}

Realizar esta tarefa, um estudo bibliográfico, torna-se importante para ter um panorama geral das pesquisas realizadas na área da formação continuada de professores e de como proceder de outras maneiras. A intenção é que se possa ampliar e multiplicar efetivamente o conhecimento sobre o campo de estudo. E para que seja possível, ao final da análise, perceber o que as pesquisas sinalizaram.

As pesquisas do primeiro eixo evidenciam que alguns professores ainda procuram os cursos de formação continuada para solucionar seus problemas ou encontrarem fórmulas para lidarem com as questões da sexualidade que emergem do cotidiano. Outro ponto que é destacado na discussão das questões de gênero e sexualidade nas escolas é o tensionamento do discurso religioso e a influência dos familiares. Por último, os próprios professores colocam a importância de não haver uma dicotomização entre teoria e prática nos cursos. Um caminho sinalizado é o compartilhamento do plano da experiência dos próprios cursistas, juntamente com a reflexão de suas práticas pedagógicas que, desse modo, permite trazer também a dimensão da prática.

No segundo eixo, foi possível perceber que há a necessidade de adensar problematizações que evidenciem novas possibilidades entre a formação continuada de professores e o cinema. Foi esse desafio, junto ao de produzir novas práticas docentes no que tange à sexualidade.

Destaca-se também que os cursos de formações investigados nas pesquisas se vinculavam a políticas de formação do Ministério da Educação (MEC), a uma "Educação Maior", nas palavras de Silvio Gallo (2008). São políticas de formação que muitas vezes separam a formação do espaço do cotidiano e da própria vida.

Assim, torna-se necessário experimentar formações sem querer capacitar, sem verdades universais, transmissão, conscientização, autoridade e com dicotomias entre teoria e prática. Por 
isso que afirmamos que existe sim a possibilidade de se construir novos modos de formação docente, uma "educação menor".

Nesse sentido, apostamos que formar é invenção, invenção de problemas, de si e do mundo. É potencializar os encontros, compartilhar um mundo nas tessituras cotidianas e lidar com as diferenças, poder fazer-emergir o campo virtual de forças que coexiste na realidade. Não se esquecendo da abertura da imprevisibilidade que se faz presente na formação. Na qual, existe um princípio ético-estético-político intrínseco à formação inventiva, uma atitude frente à formação, uma atitude de vida. Rocha, explorando a perspectiva ética-estética-política de Guattarri e Rolnik, diz:

A dimensão ética sustenta uma atitude em que o exercício do pensamento é um fator preponderante, a apreciação de valores e das situações estabelece o que potencializa ou não a vida e requer o abandono do prescrito e a abertura para iniciativas libertadoras, para uma vida mais feliz na ampliação de escolhas; a dimensão estética traz o desafio à criação de um percurso de problematização, mergulho no campo de forças que desmancham as formas e determinações já estabelecidas, favorecendo novas circunscrições do cotidiano, deslocamentos de antigas determinações. Por que poderíamos associar a estética à ética? Porque no momento em que somos afetados pelas forças e nos propomos a pensar, outros modos vão se construindo, escolhas vão acontecendo entre nós por caminhos impensados. A dimensão política situa o campo dos encontros como essencial, publicização do que faz, tomada de posição, atitude implicativa que tensiona a rede de relações, saída do lugar de espectador. A política se dá no espaço público, no fortalecimento de um entre nós (2012:46).

A formação inventiva se relaciona com um processo de produção de subjetividade e que ganha força nas micropolíticas da produção de modos de subjetivação. Um processo em que a formação é a "expressão do que somos, plano de construção e superfície de variação do que somos. [...] pensar a formação: como experiência de subjetivação, de construção de si e do mundo" (CÉSAR, 2013:13). O cinema envolve também o processo de produção de subjetividade, ele age sobre a vida, faz ver o nosso mundo diferentemente. É por meio de uma formação (inventiva) continuada de professores a partir do cinema com a temática da sexualidade, que pode desestabilizar processos de normalização, segregação, classificação e levar ao questionamento das identidades.

\section{REFERÊNCIAS}

ANTOS, Ana Cristina Ferreira. Gênero, sexualidade e diversidade na formação de professores da rede municipal de Juíz de Fora. 2012. Dissertação (Mestrado) em Educação - Universidade Católica de Petrópolis.

BASSALO, Lucélia de Moraes Braga. Heteronormatividade ou reconhecimento? Professores e professoras diante da homossexualidade. In: Reunião Anual da Associação Nacional de PósGraduação e Pesquisa em Educação, 34ạ, 2011, Natal.

Anais eletrônicos...Disponível em:http://34reuniao.anped.org.br/images/trabalhos/GT23/GT23-682\%20int.pdf. Acesso em: 25 de Agosto de 2015.

CASTRO, Alexandre Silva Bortolini. Sexualidade, gênero e diversidade: currículo e prática pedagógica. In: Reunião Anual da Associação Nacional de Pós-Graduação e Pesquisa em Educação, 35a , 2012, Porto de Galinhas. Anais eletrônicos...Disponível em: 
http://35reuniao.anped.org.br/images/stories/trabalhos/GT23\%20Trabalhos/GT23-1931_int.pdf. Acesso em: 25 de Agosto de 2015.

CÉSAR, Janaína Mariano. O que se passa nos processos formativos? O labor de um êthos na produção de si. 2013. Tese (Doutorado em Educação) - Universidade Federal do Espírito Santo, Centro de Educação.

DIAS, Rosimeri de Oliveira. Deslocamentos na formação de professores: aprendizagem de adultos, experiência e políticas cognitivas. Rio de Janeiro: Lamparina, 2011.

GALLO, Silvio. Deleuze \& a educação. Belo Horizonte: Autêntica, 2008.

GUATTARI, F. e ROLNIK, S. Micropolítica: cartografias do desejo. Petrópolis: Vozes, 1986.

JUNIOR, Donald Hugh de Barros Kerr. Cartografias da (trans)formação docente: uma experiência estética com o cinema. 2012. Tese (Doutorado) - Universidade do Vale do Rio dos Sinos, Centro de Educação.

KASTRUP, Virgínia. Aprendizagem, arte e invenção. Psicologia em Estudo, Maringá, v. 6, n. 1, p. 1727, jan./jun. 2001.

MEDEIROS, Cristiano Sant'Anna; VIERIA, Ana Letícia; VASCONCELOS, Suellen. As narrativas audiovisuais como potencializadoras das discussões sobre gênero e sexualidade. In: Seminário Nacional de Educação, Diversidade Sexual e Direitos Humanos, 3ㅇ, 2014, Vitória. Anais eletrônicos... Disponível em: http://www.gepsexualidades.com.br/resources/anais/4/1404610017. Acesso em: 19 de Março de 2015.

RIBEIRO, Cláudia Maria. No labirinto da educação infantil as falas de educadoras sobre gênero e sexualidade. In: Reunião Anual da Associação Nacional de Pós-Graduação e Pesquisa em Educação, 35a, 2012, Porto de Galinhas. Anais eletrônicos...Disponível em: http://35reuniao.anped.org.br/images/stories/trabalhos/GT23.pdf>. Acesso em: 21 de Agosto de 2015.

RIZZATO, Liane Kelen. Percepções docentes sobre a homofobia na escola: entre dissonâncias e continuidades. In: Reunião Anual da Associação Nacional de Pós-Graduação e Pesquisa em Educação, 35ạ, 2012, . Anais eletrônicos...Disponível em: <http://35reuniao.anped.org.br/images/stories/trabalhos/GT23\%20Trabalhos/GT232006_int.pdf>. Acesso em: 21 Agosto 2015.

SANTOS, Vera Marcia Marques. Pontes que se estabelecem em educação sexual: um diálogo sobre a formação continuada e os saberes das práticas pedagógicas de professoras no brasil e em Portugal. 2011. Tese (Doutorado) - Universidade do Vale do Rio dos Sinos, Centro de Educação. 
